\title{
Effect of Perilla Oil on Reducing Arteriosclerosis Risk: A Randomized Controlled Cross-Over Study
}

\author{
Erena Tokudome ${ }^{1}$, Masakazu Imamura ${ }^{2}$, Sayaka Shiomitsu ${ }^{3}$, Ryoko Miyanohara ${ }^{4}$, Emiko Hori $^{1}$, Hiroto Nishimata ${ }^{5}$, Takuma \\ Yoshinaga $^{\text {* }}$ \\ ${ }^{1}$ Division of Clinical Application, Nanpuh Hospital, Kagoshima-city, Japan \\ ${ }^{2}$ Department of Cardiology, Nanpuh Hospital, Kagoshima-city, Japan \\ ${ }^{3}$ Department of Nutrition, Nanpuh Hospital, Kagoshima-city, Japan \\ ${ }^{4}$ Department of Clinical Laboratory, Nanpuh Hospital, Kagoshima-city, Japan \\ ${ }^{5}$ Department of Gastroenterology, Nanpuh Hospital, Kagoshima-city, Japan
}

${ }^{*}$ Corresponding author: Takuma Yoshinaga, Ph.D., Division of Clinical Application, Nanpuh Hospital, 14-3 Nagata-cho, Kagoshima-city, Japan 892-8512; Tel; 81-99-226-9111, Fax; 81-99-225-8096; Email: t-yoshinaga@nanpuh.or.jp

Received: December 05, 2018; Accepted: December 12, 2018; Published: December 19, 2018;

\begin{abstract}
The risk of arteriosclerosis may be reduced by increasing the levels of $\alpha$-linolenic acid (ALA), a omega-3 polyunsaturated fatty acid. Perilla oil contains abundant ALA. This randomized crossover clinical study of perilla oil investigated its safety and effects on the levels of ALA and lipid profile in 10 subjects. Half of the subjects took 1 tablespoon of perilla oil (ALA content $=$ approximately $9.4 \mathrm{~g}$ ) and the remaining half took 1 tablespoon of olive oil (ALA content $=$ approximately $0.09 \mathrm{~g}$ ) daily for 1 week. After a 28-day washout period, each group switched and took the other oil for 1 week. Variables were measured before and after each week of oil ingestion. The ratio of low density lipoprotein cholesterol to high density lipoprotein cholesterol significantly decreased after ingestion of perilla oil ( $2.7 \pm 0.6$ vs. $2.6 \pm 0.6, P=0.037)$. The levels of ALA significantly increased after ingestion of perilla oil ( $31.6 \pm 10.32$ vs. $67.93 \pm 24.35 \mu \mathrm{g} / \mathrm{mL}, P=0.001)$. There were no adverse effects related to perilla oil. Therefore, as a dietary supplement, perilla oil has beneficial effects on the levels of ALA and lipid profile, suggesting that it contributes to a reduction in the risk of arteriosclerosis.
\end{abstract}

Keywords: Perilla oil, Olive oil, Arteriosclerosis, Vascular endothelial function, Reactive hyperemia index

\section{Introduction}

Arteriosclerosis leads to heart and cerebrovascular diseases and is the leading cause of death worldwide. Risk factors for arteriosclerosis are diabetes (DM), hypertension, dyslipidemia, obesity, and smoking [1]. Omega - 3 polyunsaturated fatty acids have attracted attention for their prophylactic effect against various disorders, including atherosclerosis, coronary artery disease, and inflammatory diseases $[2,3]$. There are reports indicating that a high intake of $\alpha$-linolenic acid (ALA), a plant-derived omega - 3 polyunsaturated fatty acid, is associated with a reduced risk of arteriosclerosis $[4,5]$. Perilla oil contains $50 \%-60 \%$ of ALA. This oil can easily be used as a daily dietary supplement. In the human body, ALA synthesizes eicosapentaenoic acid (EPA) [6]. It has been reported that EPA and docosahexaenoic acid (DHA), both omega - 3 polyunsaturated fatty acids contained in fish oil, exhibit antithrombotic and lipid-lowering actions [7, 8]. There have been few studies of perilla oil and its hypothetical effect on reducing arteriosclerosis.

ALA inhibits arteriosclerosis-associated inflammation and reduces oxidative stress, which contributes to improve vascular endothelial function $[9,10]$. Reactive hyperemia index (RHI) has been reported to be useful for evaluating vascular endothelial function. Moreover, it is a good predictor of cardiovascular disease [11, 12]. Previous studies have suggested that ALA reduces diastolic blood pressure and increase serum triacylglycerol concentration [13]. Salonen, J.T et al. showed that estimated dietary intake of linolenic acid has an inverse correlation with mean resting blood pressure [14]. However, it must be noted that overdoses of ALA, EPA, and DHA may cause blood coagulation [15].

We conducted a randomized crossover clinical trial of perilla oil to evaluate its safety and effects on the levels of ALA, lipid profile and endothelial function as markers of atherosclerotic risk.

\section{Materials and Methods}

Test diets. Perilla oil, extracted from perilla seeds, was used as the study oil. A commercially available olive oil was used as a placebo control. The ALA content of the perilla oil was $62.9 \mathrm{~g} / 100 \mathrm{~g}$, while that of the olive oil was $0.6 \mathrm{~g} / 100 \mathrm{~g}$. The ALA content was measured at the Japan Food Research Laboratories (Tokyo, Japan). Both oils were given in a dose size of 1 tablespoon as a daily supplement at breakfast for 1 week. The estimated content of ALA in each dose was approximately $9.4 \mathrm{~g}$ in the perilla oil and $0.09 \mathrm{~g}$ in the olive oil.

Subjects. Ten untreated individuals ( 4 male and 6 female) who had at least two risk factors for arteriosclerosis (aging, first-degree hypertension, dyslipidemia, DM, obesity, and smoking) were enrolled 
[16]. For the purposes of this study, hypertension was defined as a systolic blood pressure of 140 to $159 \mathrm{mmHg}$ or a diastolic blood pressure of 90 to $99 \mathrm{mmHg}$. Dyslipidemia was defined as a lowdensity lipoprotein cholesterol (LDL-C) $\geqq 140 \mathrm{mg} / \mathrm{dL}$. Diabetes was defined as a fasting blood glucose concentration $\geqq 126 \mathrm{mg} / \mathrm{dL}$, or a hemoglobin A1c (HbA1c) $\geqq 6.37 \%$. Obesity was defined as a body mass index (BMI) $\geqq 25 \mathrm{~kg} / \mathrm{m}^{2}$. Smoking was recorded as a risk factor regardless of whether it was past or present. The definition of aging was 45 years or older men and postmenopausal women. Table 1 shows the subjects' characteristics. The study was approved by the Ethics Committee of Nanpuh Hospital, Kagoshima Kyosaikai, Public Interest Inc. Association, Japan. Clinical examinations were performed according to the principles of the Declaration of Helsinki. Written informed consent was obtained from all individuals.

Table 1. Characteristics of subjects taking perilla oil or olive oil supplements

\begin{tabular}{|c|c|c|c|c|c|c|c|}
\hline No & Age & Sex & $\begin{array}{c}\text { hyperten- } \\
\text { sion }\end{array}$ & $\begin{array}{c}\text { dyslipid- } \\
\text { emia }\end{array}$ & diabetes & obesity & $\begin{array}{c}\text { Smok- } \\
\text { ing }\end{array}$ \\
\hline 1 & 55 & Male & No & Yes & No & No & No \\
\hline 2 & 56 & Female & No & Yes & No & No & No \\
\hline 3 & 44 & Male & No & Yes & No & No & Yes \\
\hline 4 & 57 & Female & Yes & Yes & No & No & No \\
\hline 5 & 59 & Female & No & Yes & No & No & No \\
\hline 6 & 47 & Male & No & No & No & Yes & Yes \\
\hline 7 & 50 & Female & Yes & Yes & No & No & No \\
\hline 8 & 56 & Female & No & No & No & Yes & No \\
\hline 9 & 42 & Male & Yes & Yes & No & Yes & Yes \\
\hline 10 & 56 & Female & Yes & Yes & No & Yes & No \\
\hline
\end{tabular}

Study design. This study was designed as a crossover method. The 10 subjects were randomly divided into two groups of 5, the first group took perilla oil daily for 1 week and the second group took olive oil. After a 28-day washout period, the groups were reversed, with the first group took olive oil daily for 1 week and the second group took perilla oil (Table 2).

Table 2. Protocol of clinical study design

\begin{tabular}{|l|c|c|c|c|c|c|c|}
\hline & \multicolumn{3}{|c|}{$1^{\text {st period }}$} & $\begin{array}{c}\text { WO } \\
\text { term }\end{array}$ & \multicolumn{3}{c|}{$2^{\text {nd }}$ period } \\
\hline & Day 1 & $\begin{array}{c}\text { Day } \\
2-7\end{array}$ & Day 8 & $\begin{array}{c}\text { Day } \\
9-35\end{array}$ & Day 36 & $\begin{array}{c}\text { Day } \\
37-42\end{array}$ & Day 43 \\
\hline Examination & $\bullet$ & - & $\bullet$ & - & $\bullet$ & - & $\bullet$ \\
\hline BMI $^{1}$ & $\bullet$ & - & $\bullet$ & - & $\bullet$ & - & $\bullet$ \\
\hline Blood pressure & $\bullet$ & - & $\bullet$ & - & $\bullet$ & - & $\bullet$ \\
\hline Blood test & $\bullet$ & - & $\bullet$ & - & $\bullet$ & - & $\bullet$ \\
\hline RHI ${ }^{2}$ & $\bullet$ & - & $\bullet$ & - & $\bullet$ & - & $\bullet$ \\
\hline Intake & $\bullet$ & $\bullet$ & - & - & $\bullet$ & $\bullet$ & - \\
\hline
\end{tabular}

${ }^{1}$ Body mass index $\left(\mathrm{kg} / \mathrm{m}^{2}\right),{ }^{2}$ Reactive hyperemia index (-), ${ }^{3}$ Washout
Variables were measured before and after each 1-week period of oil ingestion. All measurements at the beginning of each period were completed on the first day of the period before the supplement was given. The measurements after each period were taken the next day of the last oil supplement.

Physical parameters were measured including blood pressure, BMI, RHI, and blood examinations. RHI, a measure of peripheral endothelial function, was assessed using peripheral arterial tonometry (EndoPAT 2000; Itamar Medical, Caesarea, Israel) according to the manufacturer's instructions. Serum levels of aspartate and alanine aminotransferase, total protein, $\gamma$-glutamyl transferase, and C-reactive protein were determined by latex agglutination using a BM6050 analyzer (Kyowa-Medex Co., Ltd., Tokyo, Japan). Serum levels of uric acid, blood urea nitrogen, glucose, triglycerides, high density lipoprotein cholesterol (HDL-C), LDL-C, and HbA1c were measured using a BioMajesty JCA-BM6050 analyzer (JEOL Ltd., Tokyo, Japan). The white blood cell (WBC), red blood cell (RBC), and platelet counts were measured with an XE-5000 Hematology Analyzer (Sysmex, Co., Hyogo, Japan). Plasma fatty acids (lauric, myristic, myristoleic, myristoleic, palmitic, palmitoleic, stearic, oleic, linoleic, $\gamma$-linolenic, $\alpha$-linolenic, arachidic, eicosenoic, eicosadienoic, 5-8-11 eicosatrienoic, dihomo- $\gamma$-linolenic, arachidonic, eicosapentaenoic, behenic, erucic, docosatetraenoic, docosapentaenoic, lignoceric, docosahexaenoic, and nervonic acids) were measured by SRL Inc (Tokyo, Japan).

Subjects were interviewed regarding their intake of the test oils and any symptoms they experienced during the study.

Statistical analysis. Measured values are expressed as means \pm standard deviation. The data were assessed using a paired $t$-test to compare results before and after ingestion of each oil. Data were analyzed using SPSS Version 25 (IBM Co., Armonk, NY, USA). A value of $P<0.05$ was considered statistically significant.

\section{Results}

Physical parameters. There were no significant differences in blood pressure, BMI, or RHI before and after the week-long interventions with perilla oil or olive oil (Table 3 ).

Table 3. Physical parameters in subjects taking perilla oil or olive oil

\begin{tabular}{|l|c|c|c|c|}
\hline & Test oils & Before & After & P-value \\
\hline $\begin{array}{l}\text { Systolic blood } \\
\text { pressure (mmHg) }\end{array}$ & Perilla oil & $138.6 \pm 17.2$ & $139.4 \pm 19.0$ & 0.739 \\
\cline { 2 - 5 } & Olive oil & $138.5 \pm 12.0$ & $135.5 \pm 12.5$ & 0.380 \\
\hline $\begin{array}{l}\text { Diastolic blood } \\
\text { pressure (mmHg) }\end{array}$ & Perilla oil & $87.7 \pm 12.6$ & $85.4 \pm 14.0$ & 0.090 \\
\cline { 2 - 5 } & Olive oil & $84.8 \pm 10.7$ & $84.0 \pm 7.9$ & 0.658 \\
\hline $\begin{array}{l}\text { Body Mass Index } \\
\text { (kg/m²) }\end{array}$ & Perilla oil & $23.5 \pm 2.7$ & $23.6 \pm 2.8$ & 0.711 \\
\cline { 2 - 5 } & Olive oil & $23.5 \pm 2.9$ & $23.4 \pm 2.9$ & 0.136 \\
\hline $\begin{array}{l}\text { Reactive } \\
\text { hyperemia index } \\
(-)\end{array}$ & Perilla oil & $1.59 \pm 0.41$ & $1.68 \pm 0.50$ & 0.571 \\
\cline { 2 - 5 } & Olive oil & $1.57 \pm 0.32$ & $1.76 \pm 0.58$ & 0.100 \\
\hline
\end{tabular}

Values are presented as mean \pm standard deviation; $\mathrm{n}=10$. 
Biochemical markers. After a week of perilla oil, the LDL-C/ HDL-C ratio decreased significantly from $2.7 \pm 0.6$ to $2.6 \pm 0.6$ $(P=0.037$, Fig. 1A). There was no statistically significant difference in the LDL-C / HDL-C ratio after subjects ingested olive oil $(2.9 \pm 0.8$ before vs. $2.8 \pm 0.7$ after, $P=0.314$, Fig. 1B). Perilla oil thus improved the LDL-C / HDL-C ratio.
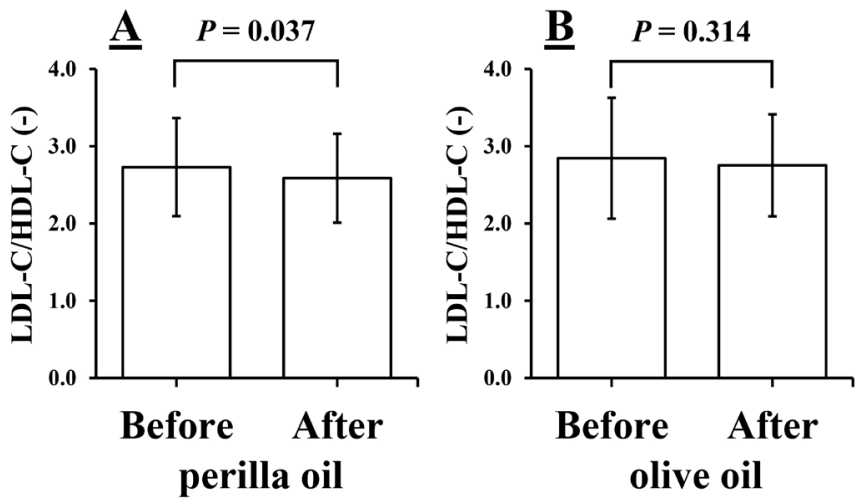

Figure 1. Ratios of low density lipoprotein cholesterol (LDL-C) to high density lipoprotein cholesterol (HDL-C) before and after 1 week of intake of perilla oil (A) or olive oil (B). Values are presented as mean \pm standard deviation; $\mathrm{n}=10$.

With the exception of significant decrease of the platelet count after a week of olive oil, none of the other biochemical or hematologic markers differed significantly before and after either perilla oil or olive oil (Table 4).

Fatty acids. We compared the levels of ALA before and after test oil intake. Fig. 2 shows the result of the levels of ALA before and after 1 week of intake of perilla oil or olive oil, respectively. The levels of ALA increased significantly after intake of perilla oil (31.60 \pm 10.32 vs. $67.93 \pm 24.35 \mu \mathrm{g} / \mathrm{mL}, P=0.001$, Fig. $2 \mathrm{~A}$ ), while the levels did not change after intake of olive oil ( $30.52 \pm 10.34$ vs. $32.74 \pm 21.26 \mu \mathrm{g} / \mathrm{mL}$, $P=0.702$, Fig. 2B).
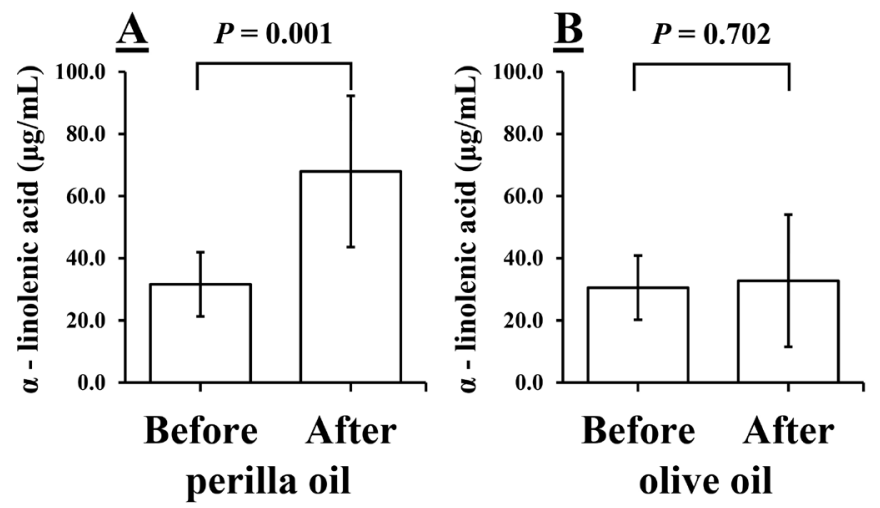

Figure 2. Levels of $\boldsymbol{\alpha}$-linolenic acid before and after 1 week of intake of perilla oil (A) or olive oil (B). Values are presented as mean \pm standard deviation; $\mathrm{n}=10$.

The levels of EPA also increased significantly after perilla oil but not after olive oil (perilla oil: $46.88 \pm 16.40$ vs. $64.43 \pm 31.32 \mu \mathrm{g} / \mathrm{mL}, P$ $=0.023$, Fig. 3 A; olive oil: $60.44 \pm 44.62$ vs. $53.90 \pm 28.36 \mu \mathrm{g} / \mathrm{mL}, P=$ 0.598, Fig. 3B).
Table 4. Biochemical and hematology markers before and after ingesting perilla oil or olive oil for 1 week

\begin{tabular}{|c|c|c|c|c|}
\hline & Group & Before & After & $\mathbf{P}$ \\
\hline \multirow{2}{*}{$\begin{array}{l}\text { Aspartate } \\
\text { aminotransferase } \\
(\mathrm{IU} / \mathrm{L})\end{array}$} & Perilla oil & $22.0 \pm 6.5$ & $24.0 \pm 7.2$ & 0.219 \\
\hline & Olive oil & $21.6 \pm 4.9$ & $22.5 \pm 6.2$ & 0.235 \\
\hline \multirow{2}{*}{$\begin{array}{l}\text { Alanine } \\
\text { aminotransferase } \\
(\mathrm{IU} / \mathrm{L})\end{array}$} & Perilla oil & $26.2 \pm 15.4$ & $27.8 \pm 15.8$ & 0.437 \\
\hline & Olive oil & $26.4 \pm 15.8$ & $26.5 \pm 17.6$ & 0.968 \\
\hline \multirow{2}{*}{ Total protein $(\mathrm{g} / \mathrm{dL})$} & Perilla oil & $7.0 \pm 0.3$ & $7.0 \pm 0.4$ & 0.763 \\
\hline & Olive oil & $7.1 \pm 0.3$ & $7.0 \pm 0.3$ & 0.273 \\
\hline \multirow{2}{*}{$\begin{array}{l}\gamma \text {-glutamyl } \\
\text { transferase (IU/L) }\end{array}$} & Perilla oil & $42.8 \pm 31.1$ & $42.6 \pm 30.6$ & 0.937 \\
\hline & Olive oil & $48.0 \pm 38.5$ & $47.1 \pm 38.2$ & 0.780 \\
\hline \multirow{2}{*}{ Uric acid (mg/dL) } & Perilla oil & $5.6 \pm 1.7$ & $5.6 \pm 1.6$ & 0.825 \\
\hline & Olive oil & $5.8 \pm 1.6$ & $5.9 \pm 1.5$ & 0.672 \\
\hline \multirow{2}{*}{$\begin{array}{l}\text { Blood urea nitrogen } \\
(\mathrm{mg} / \mathrm{dL})\end{array}$} & Perilla oil & $13.3 \pm 2.6$ & $12.0 \pm 1.6$ & 0.229 \\
\hline & Olive oil & $12.6 \pm 2.9$ & $13.7 \pm 3.6$ & 0.390 \\
\hline \multirow{2}{*}{ Triglyceride (mg/dL) } & Perilla oil & $129.2 \pm 71.8$ & $137.3 \pm 70.0$ & 0.585 \\
\hline & Olive oil & $122.6 \pm 59.0$ & $150.9 \pm 108.7$ & 0.306 \\
\hline \multirow{2}{*}{$\begin{array}{l}\text { High density } \\
\text { lipoprotein } \\
\text { cholesterol (HDL-C) } \\
(\mathrm{mg} / \mathrm{dL})\end{array}$} & Perilla oil & $64.4 \pm 12.8$ & $65.6 \pm 14.7$ & 0.549 \\
\hline & Olive oil & $64.1 \pm 14.0$ & $62.8 \pm 12.2$ & 0.593 \\
\hline \multirow{2}{*}{$\begin{array}{l}\text { Low-density } \\
\text { lipoprotein } \\
\text { cholesterol (LDL-C) } \\
\text { (mg/dL) }\end{array}$} & Perilla oil & $171.0 \pm 31.5$ & $165.0 \pm 30.5$ & 0.400 \\
\hline & Olive oil & $174.4 \pm 27.7$ & $168.3 \pm 32.8$ & 0.147 \\
\hline \multirow{2}{*}{$\begin{array}{l}\text { C-reactive protein } \\
(\mathrm{mg} / \mathrm{dL})\end{array}$} & Perilla oil & $0.2 \pm 0.2$ & $0.3 \pm 0.6$ & 0.569 \\
\hline & Olive oil & $0.1 \pm 0.1$ & $0.1 \pm 0.1$ & 0.835 \\
\hline \multirow{2}{*}{$\begin{array}{l}\text { White blood cell } \\
\text { count }\left(10^{\wedge} 2 / \mu \mathrm{L}\right)\end{array}$} & Perilla oil & $55.2 \pm 8.3$ & $54.4 \pm 10.8$ & 0.741 \\
\hline & Olive oil & $53.3 \pm 9.7$ & $59.2 \pm 6.8$ & 0.050 \\
\hline \multirow{2}{*}{$\begin{array}{l}\text { Red blood cell count } \\
\left(10^{4} / \mu \mathrm{L}\right)\end{array}$} & Perilla oil & $445.5 \pm 44.9$ & $444.4 \pm 40.0$ & 0.828 \\
\hline & Olive oil & $448.4 \pm 42.1$ & $446.7 \pm 37.6$ & 0.564 \\
\hline \multirow{2}{*}{$\begin{array}{l}\text { Platelet count }\left(10^{4} /\right. \\
\mu \mathrm{L})\end{array}$} & Perilla oil & $26.0 \pm 9.8$ & $26.1 \pm 10.1$ & 0.628 \\
\hline & Olive oil & $27.5 \pm 10.7$ & $26.3 \pm 11.0$ & $0.008^{*}$ \\
\hline \multirow{2}{*}{ Blood sugar (mg/dL) } & Perilla oil & $100.5 \pm 10.5$ & $98.5 \pm 5.5$ & 0.363 \\
\hline & Olive oil & $99.8 \pm 9.3$ & $101.1 \pm 11.0$ & 0.537 \\
\hline \multirow{2}{*}{$\begin{array}{l}\text { Hemoglobin A1c } \\
(\%)\end{array}$} & Perilla oil & $5.4 \pm 0.4$ & $5.3 \pm 0.4$ & 0.394 \\
\hline & Olive oil & $5.3 \pm 0.4$ & $5.4 \pm 0.4$ & 0.096 \\
\hline
\end{tabular}

Values are presented as mean \pm standard deviation; $\mathrm{n}=10$.

*Significant difference in values analyzed with a paired $t$-test.

None of the other fatty acids differed significantly before and after intake of either oil (Table 5). 
Takuma Yoshinaga (2018) Effect of Perilla Oil on Reducing Arteriosclerosis Risk: A Randomized Controlled Cross-Over Study

Table 5. Levels of Fatty acid before and after ingestion of perilla oil or olive oil for 1 week

\begin{tabular}{|c|c|c|c|c|}
\hline & Group & Before & After & $\mathbf{P}$ \\
\hline \multirow[t]{2}{*}{ Lauric acid $(\mu \mathrm{g} / \mathrm{mL})$} & Perilla oil & $1.96 \pm 1.21$ & $2.37 \pm 1.19$ & 0.156 \\
\hline & Olive oil & $2.83 \pm 2.18$ & $2.80 \pm 1.56$ & 0.974 \\
\hline \multirow[t]{2}{*}{ Myristic acid $(\mu \mathrm{g} / \mathrm{mL})$} & Perilla oil & $25.65 \pm 11.17$ & $29.55 \pm 14.12$ & 0.160 \\
\hline & Olive oil & $28.21 \pm 10.11$ & $31.96 \pm 18.92$ & 0.504 \\
\hline \multirow[t]{2}{*}{ Myristoleic acid $(\mu \mathrm{g} / \mathrm{mL})$} & Perilla oil & $1.45 \pm 0.68$ & $2.04 \pm 1.59$ & 0.147 \\
\hline & Olive oil & $1.50 \pm 0.62$ & $2.48 \pm 2.32$ & 0.223 \\
\hline \multirow[t]{2}{*}{ Myristoleic acid (\%) } & Perilla oil & $0.04 \pm 0.02$ & $0.05 \pm 0.04$ & 0.153 \\
\hline & Olive oil & $0.04 \pm 0.01$ & $0.06 \pm 0.06$ & 0.283 \\
\hline \multirow[t]{2}{*}{ Palmitic acid $(\mu \mathrm{g} / \mathrm{mL})$} & Perilla oil & $806.65 \pm 179.01$ & $840.05 \pm 199.55$ & 0.271 \\
\hline & Olive oil & $817.21 \pm 168.76$ & $862.76 \pm 261.01$ & 0.522 \\
\hline \multirow[t]{2}{*}{ Palmitoleic acid $(\mu \mathrm{g} / \mathrm{mL})$} & Perilla oil & $64.77 \pm 25.50$ & $73.94 \pm 39.24$ & 0.247 \\
\hline & Olive oil & $65.75 \pm 37.47$ & $73.91 \pm 33.71$ & 0.445 \\
\hline \multirow[t]{2}{*}{ Stearic acid $(\mu \mathrm{g} / \mathrm{mL})$} & Perilla oil & $260.59 \pm 41.50$ & $274.05 \pm 45.73$ & 0.106 \\
\hline & Olive oil & $262.54 \pm 43.77$ & $276.61 \pm 57.94$ & 0.346 \\
\hline \multirow[t]{2}{*}{ Oleic acid $(\mu \mathrm{g} / \mathrm{mL})$} & Perilla oil & $740.99 \pm 233.84$ & $776.63 \pm 258.10$ & 0.503 \\
\hline & Olive oil & $718.07 \pm 198.32$ & $831.36 \pm 306.45$ & 0.219 \\
\hline \multirow[t]{2}{*}{ Linoleic acid $(\mu \mathrm{g} / \mathrm{mL})$} & Perilla oil & $1166.83 \pm 146.40$ & $1155.99 \pm 115.14$ & 0.654 \\
\hline & Olive oil & $1154.53 \pm 119.03$ & $1169.50 \pm 216.89$ & 0.799 \\
\hline \multirow[t]{2}{*}{$\gamma$-linolenic acid $(\mu \mathrm{g} / \mathrm{mL})$} & Perilla oil & $13.84 \pm 5.74$ & $12.25 \pm 3.03$ & 0.394 \\
\hline & Olive oil & $14.07 \pm 3.57$ & $14.31 \pm 3.87$ & 0.891 \\
\hline \multirow[t]{2}{*}{ Arachidic acid $(\mu \mathrm{g} / \mathrm{mL})$} & Perilla oil & $9.37 \pm 1.53$ & $9.59 \pm 1.57$ & 0.340 \\
\hline & Olive oil & $9.38 \pm 1.54$ & $9.55 \pm 1.57$ & 0.623 \\
\hline \multirow[t]{2}{*}{ Eicosenoic acid $(\mu \mathrm{g} / \mathrm{mL})$} & Perilla oil & $5.35 \pm 2.05$ & $5.17 \pm 1.88$ & 0.515 \\
\hline & Olive oil & $4.76 \pm 1.32$ & $5.78 \pm 3.33$ & 0.276 \\
\hline \multirow[t]{2}{*}{ Eicosadienoic acid $(\mu \mathrm{g} / \mathrm{mL})$} & Perilla oil & $8.89 \pm 2.30$ & $8.63 \pm 2.43$ & 0.562 \\
\hline & Olive oil & $8.48 \pm 1.85$ & $8.94 \pm 3.35$ & 0.604 \\
\hline \multirow[t]{2}{*}{ 5-8-11 eicosatrienoic acid $(\mu \mathrm{g} / \mathrm{mL})$} & Perilla oil & $3.18 \pm 0.82$ & $2.9 \pm 1.31$ & 0.410 \\
\hline & Olive oil & $2.96 \pm 1.04$ & $3.26 \pm 1.18$ & 0.387 \\
\hline \multirow[t]{2}{*}{ Dihomo- $\gamma$-linolenic acid $(\mu \mathrm{g} / \mathrm{mL})$} & Perilla oil & $47.76 \pm 9.52$ & $44.83 \pm 13.35$ & 0.242 \\
\hline & Olive oil & $51.63 \pm 21.62$ & $51.38 \pm 16.84$ & 0.945 \\
\hline \multirow[t]{2}{*}{ Arachidonic acid $(\mu \mathrm{g} / \mathrm{mL})$} & Perilla oil & $261.62 \pm 42.74$ & $253.67 \pm 50.44$ & 0.261 \\
\hline & Olive oil & $267.28 \pm 45.99$ & $258.96 \pm 44.81$ & 0.226 \\
\hline \multirow[t]{2}{*}{ Behenic acid $(\mu \mathrm{g} / \mathrm{mL})$} & Perilla oil & $25.2 \pm 5.21$ & $25.59 \pm 5.14$ & 0.607 \\
\hline & Olive oil & $25.83 \pm 4.67$ & $25.64 \pm 5.00$ & 0.785 \\
\hline \multirow[t]{2}{*}{ Erucic acid $(\mu \mathrm{g} / \mathrm{mL})$} & Perilla oil & $1.04 \pm 0.07$ & $1.12 \pm 0.14$ & 0.121 \\
\hline & Olive oil & $1.09 \pm 0.12$ & $1.14 \pm 0.21$ & 0.475 \\
\hline \multirow[t]{2}{*}{ Docosatetraenoic acid $(\mu \mathrm{g} / \mathrm{mL})$} & Perilla oil & $6.82 \pm 1.36$ & $6.67 \pm 1.80$ & 0.726 \\
\hline & Olive oil & $6.77 \pm 1.53$ & $7.04 \pm 2.02$ & 0.666 \\
\hline \multirow[t]{2}{*}{ Docosapentaenoic acid $(\mu \mathrm{g} / \mathrm{mL})$} & Perilla oil & $19.82 \pm 5.39$ & $22.67 \pm 8.14$ & 0.126 \\
\hline & Olive oil & $20.24 \pm 5.70$ & $19.5 \pm 6.72$ & 0.505 \\
\hline \multirow[t]{2}{*}{ Lignoceric acid $(\mu \mathrm{g} / \mathrm{mL})$} & Perilla oil & $22.14 \pm 3.74$ & $22.57 \pm 4.06$ & 0.580 \\
\hline & Olive oil & $22.68 \pm 2.91$ & $22.52 \pm 3.93$ & 0.778 \\
\hline \multirow[t]{2}{*}{ Docosahexaenoic acid $(\mu \mathrm{g} / \mathrm{mL})$} & Perilla oil & $139.94 \pm 42.19$ & $142.82 \pm 48.54$ & 0.644 \\
\hline & Olive oil & $152 \pm 51.35$ & $140.64 \pm 42.32$ & 0.134 \\
\hline \multirow[t]{2}{*}{ Nervonic acid $(\mu \mathrm{g} / \mathrm{mL})$} & Perilla oil & $42.39 \pm 7.28$ & $41.71 \pm 5.64$ & 0.641 \\
\hline & Olive oil & $43.76 \pm 6.12$ & $42.04 \pm 5.86$ & 0.197 \\
\hline
\end{tabular}

Values are presented as mean \pm standard deviation; $\mathrm{n}=10$ 

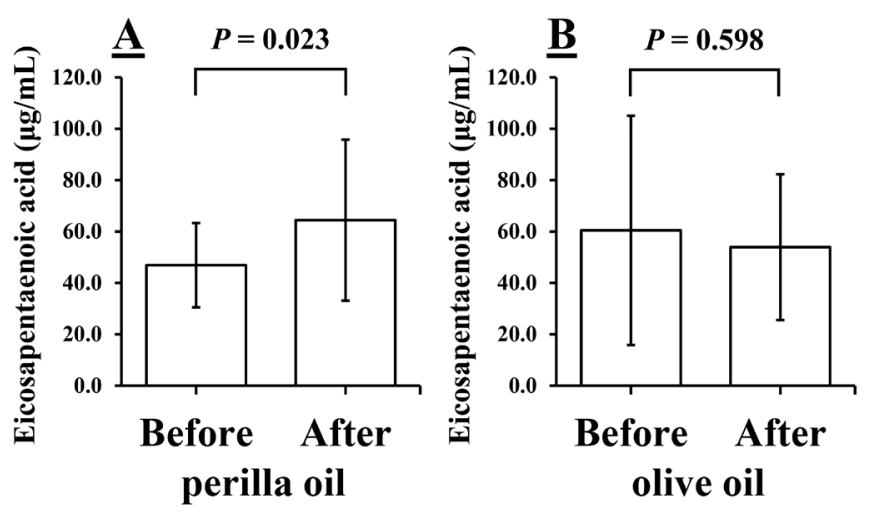

Figure 3. Levels of Eicosapentaenoic acid before and after 1 week of intake of perilla oil (A) or olive oil (B). Values are presented as mean \pm standard deviation; $\mathrm{n}=10$.

Safety. There were no serious adverse events related to the intervention. There were also no significant changes in $\mathrm{WBC}, \mathrm{RBC}$, and platelet counts after ingestion of perilla oil.

\section{Discussion}

Prevention of arteriosclerosis which leads to cardiovascular disease is very important [17]. Given its apparent preventing effects, we focused our experiments on ALA and confirmed that a week's daily intake of perilla oil significantly increased the plasma levels of ALA and EPA. It has been reported that $11 \%$ to $19 \%$ of ALA ingested from a meal is converted to EPA or DHA through an in vivo chain extension process [18]. In this study, ALA and EPA increased significantly after intake of perilla oil.. The levels of LDL-C and HDL-C were not changed after intake of perilla oil, while the LDL-C/HDL-C ratio was significantly improve. Recently, the LDL-C/HDL-C ratio has been regarded as an important index of arteriosclerosis. Even in the presence of normal levels of LDL-C, myocardial infarction may occur with low levels of HDL-C. Prevention of arteriosclerosis thus necessitates balancing the levels of LDL-C and HDL-C, which supports the concept of the LDL-C/HDL-C ratio as an important index [19, 20]. Previous study has been reported that Omega - 3 polyunsaturated fatty acids treatments reduced serum total cholesterol and LDL-C and increased HDL-C [21]. Improving of HDL-C / LDL-C ratio is important for prevention of arteriosclerosis [22]. Improving the ratio would be important to reduce arteriosclerosis risk.

No other significant differences except the changes in the LDL-C/ HDL-C ratio and levels of ALA and EPA after ingestion of perilla oils were found in any of the variables we measured. There were no changes in blood pressure or BMI. Overdoses of ALA, EPA, and DHA may affect blood coagulation [15]. However, the platelet counts in our subjects did not change significantly before and after ingestion of perilla oil, and no adverse events related to blood clotting were occurred. No adverse events occurred. Therefore, the daily ingestion of perilla oil for 1 week appears to be safe.

RHI evaluates the vasodilator functions of vascular endotheliumderived vasodilators [23]. In this study, RHI was measured as an indicator of vascular endothelial function. Long-term treatment with EPA has been reported to improve impaired endothelium-dependent relaxations of atherosclerotic blood vessels [24]. In this study, we expected that the RHI might improve by perilla oil-induced increases in ALA, but there was no significant difference in the RHI before and after perilla oil.

Because ours was a short-term study with ingestion of perilla oil occurring for only 1 week and involving a small number of subjects, the study may have been underpowered to detect a significant difference in the RHI. Future studies in large numbers of individuals with long-term intake of perilla oil are needed.

\section{Conclusion}

We confirmed significant increases in the plasma levels of ALA and improvement in the LDL-C/HDL-C ratio induced by intake of perilla oil. To the extent that improvement of those markers may have a preventive effect against arteriosclerosis, our study suggests that ingestion of perilla oil may be of value in decreasing or preventing arteriosclerosis. Confirming this hypothesis will require long-term administration of perilla oil supplementation and adequate numbers of subjects so that cardiovascular outcomes can be assessed.

\section{Acknowledgments}

We are grateful to J. Saito and M. Kamiaraiso and the staff of the Department of Clinical Laboratory, Nanpuh Hospital for their tireless efforts in the carrying out this study. We also thank the study subjects for their participation.

\section{Conflict of Interest}

No potential conflicts of interest were disclosed.

\section{References}

1. Amraoui M.E, Hjira, N. (2018) [Atypical and revelatory livedo reticularis!?]. Pan Afr Med J 29, 91.[Crossref]

2. Connor W.E. (2000) Importance of n-3 fatty acids in health and disease. Am J Clin Nutr 71, 171S-5S. [Crossref]

3. Takeuchi H, Sakurai C, Noda R, Sekine, S, et al. (2007) Antihypertensive effect and safety of dietary alpha-linolenic acid in subjects with high-normal blood pressure and mild hypertension. J Oleo Sci 56, 347-360. [Crossref]

4. Lanzmann-Petithory D.(2001) Alpha-linolenic acid and cardiovascular diseases. $J$ Nutr Health Aging 5, 179-183. [Crossref]

5. Hu FB, Stampfer MJ, Manson JE, Rimm, EB, et al. (1999) Dietary intake of alphalinolenic acid and risk of fatal ischemic heart disease among women. Am J Clin Nutr 69, 890-897. [Crossref]

6. Burdge GC, Calder PC. (2005) Conversion of alpha-linolenic acid to longerchain polyunsaturated fatty acids in human adults. Reprod Nutr Dev 45, 581-597. [Crossref]

7. Dyerberg J, Bang H.O, Stoffersen E, Moncada S, et al. (1978) Eicosapentaenoic acid and prevention of thrombosis and atherosclerosis? Lancet 2, 117-119. [Crossref]

8. Bonaa K.H, Bjerve K.S, Nordoy A. (1992) Habitual fish consumption, plasma phospholipid fatty acids, and serum lipids: the Tromso study. Am J Clin Nutr 55, 1126-1134. [Crossref]

9. Han H, Yan, P, Chen L, Luo, C, et al. (2015) Flaxseed Oil Containing alpha -Linolenic Acid Ester of Plant Sterol Improved Atherosclerosis in ApoE Deficient Mice. Oxid Med Cell Longev 958217.

10. Hong S.H, Kim M, Noh J.S, Song Y.O. (2016) Perilla Oil Reduces Fatty Streak Formation at Aortic Sinus via Attenuation of Plasma Lipids and Regulation of Nitric Oxide Synthase in ApoE KO Mice. Lipids 51, 1161-1170. [Crossref]

11. Mudau M, Genis A, Lochner A, Strijdom H. (2012) Endothelial dysfunction: the early predictor of atherosclerosis. Cardiovasc J Afr 23, 222-231. [Crossref]

12. Moncada S, Palmer RM, Higgs EA. (1988) The discovery of nitric oxide as the endogenous nitrovasodilator. Hypertension 12, 365-372. [Crossref]

13. Bemelmans W.J, Muskiet F.A, Feskens E.J, Vries J.H, et al. (2000) Associations of alpha-linolenic acid and linoleic acid with risk factors for coronary heart disease. Eur J Clin Nutr 54, 865-871. [Crossref] 
14. Salonen J.T, Salonen R, Ihanainen M, Parviainen, M, et al. (1987) Vitamin C deficiency and low linolenate intake associated with elevated blood pressure: the Kuopio Ischaemic Heart Disease Risk Factor Study. J Hypertens Suppl 5, S521-4. [Crossref]

15. von Houwelingen R, Nordoy, A, van, der Beek E, Houtsmuller U, et al. (1987) Effect of a moderate fish intake on blood pressure, bleeding time, hematology, and clinical chemistry in healthy males. Am J Clin Nutr 46, 424-436. [Crossref]

16. Scheuner M.T. (2003) Genetic evaluation for coronary artery disease. Genet Med 5, 269-285. [Crossref]

17. Wang Y.Z, Yang L, Li C.F. (2018) Protective effect of atorvastatin meditated by HMGCR gene on diabetic rats with atherosclerosis: An in vivo and in vitro study. Biomed Pharmacother 104, 240-251. [Crossref]

18. Emken E.A, Adlof R.O, Gulley R.M. (1994) Dietary linoleic acid influences desaturation and acylation of deuterium-labeled linoleic and linolenic acids in young adult males. Biochim Biophys Acta 1213, 277-288. [Crossref]

19. Yokokawa H, Yasumura S, Tanno K, Ohsawa, M, et al. (2011) Serum lowdensity lipoprotein to high-density lipoprotein ratio as a predictor of future acute myocardial infarction among men in a 2.7-year cohort study of a Japanese northern rural population. $J$ Atheroscler Thromb 18, 89-98. [Crossref]
20. Tomosugi N, Yamamoto S, Takeuchi M, Yonekura, H, et al. (2017) Effect of Collagen Tripeptide on Atherosclerosis in Healthy Humans. J Atheroscler Thromb 24, 530-538. [Crossref]

21. Shen T, Xing G, Zhu J, Zhang, S, et al. (2017) Effects of 12-week supplementation of marine Omega-3 PUFA-based formulation Omega3Q10 in older adults with prehypertension and/or elevated blood cholesterol. Lipids Health Dis 16, 253. [Crossref]

22. Kanaoka T, Takahashi J, Wakamatsu Y, Ishii, K, et al. (2012) Lowered postoperative ldl-c/hdl-C ratio reduces later cardiovascular events after abdominal aortic aneurysm surgery. Ann Vasc Dis 5, 36-44. [Crossref]

23. Axtell A.L, Gomari F.A, Cooke J.P. (2010) Assessing endothelial vasodilator function with the Endo-PAT 2000. J Vis Exp. [Crossref]

24. Tagawa H, Shimokawa H, Tagawa T, Kuroiwa-Matsumoto M, Hirooka Y, et al. (1999) Long-term treatment with eicosapentaenoic acid augments both nitric oxide-mediated and non-nitric oxide-mediated endothelium-dependent forearm vasodilatation in patients with coronary artery disease. J Cardiovasc Pharmacol 33, 633-640. [Crossref]

\section{Citation:}

Erena Tokudome, Masakazu Imamura, Sayaka Shiomitsu, Ryoko Miyanohara, Emiko Hori, Hiroto Nishimata, Takuma Yoshinaga (2018) Effect of Perilla Oil on Reducing Arteriosclerosis Risk: A Randomized Controlled Cross-Over Study. J Clin Res Med Volume 1(4): 1-6. 